\title{
ABSTRACTS
}

\section{BURDEN OF FATAL AND HOSPITALISED INJURY IN FIJI: FINDINGS FROM A POPULATION-BASED INJURY SURVEILLANCE SYSTEM}

doi:10.1136/injuryprev-2012-040590w.65

${ }^{1}$ I Wainiqolo, ${ }^{1}$ B Kafoa, ${ }^{2}$ B Kool, ${ }^{2} \mathrm{~J}$ Herman, ${ }^{1}$ E McCaig, ${ }^{2}$ S Ameratunga. ${ }^{1}$ Fiji National University, Fiji; ${ }^{2}$ University of Auckland, New Zealand

Background Despite estimates indicating high-rates of injuries in low-and middle-income countries, population-based data from Pacific Island nations are scant.

Aim/Objectives/Purpose To describe the epidemiology of injury-related deaths and hospitalisations in Fiji.

Methods The Fiji Injury Surveillance in Hospitals (FISH) database prospectively collected data on all injury deaths and primary admissions to hospital ( $\geq 12 \mathrm{~h}$ stay) in Viti Levu, Fiji during a 12-month period (October 2005-September 2006).

Results/0utcomes The 2233 injury cases identified corresponded to an annualised incidence rate of $343 / 100000$. Eighty percent of cases were aged less than 45 years, and males had twice the injury rate of females. Most injuries (73.8\%) were unintentional. Among intentional injuries, assaults were highest amongst Fijians and self harm injuries highest amongst Indians. The crude rates of death and hospitalisation were 37.8 and 316 per 100000 population, respectively. Among the 246 fatalities (71\% of whom died before hospitalisation), the leading causes were road traffic injury (28\%) and hanging (25\%), with the principal injury most commonly noted to be asphyxia or head injury. Among the 2059 hospital admissions, the leading causes were falls $(30 \%)$ and being struck by a person or object (23\%); fractures and open wounds were the commonest types of injury. Alcohol was considered a contributing factor in at least $12 \%$ of injury events.

Significance/Contribution to the Field This study has identified the high risk groups of fatal and serious non-fatal injuries that can guide the development of national strategies and help prioritise monitoring, evaluation and research strategies to address injury hazards and determinants. 